\title{
Article \\ Star Wars? Space Weather and Electricity Market: Evidence from China
}

\author{
Tong $\mathrm{Wu}^{1}{ }^{1}$, Zhe You ${ }^{1, *}$, Mengqi Gong ${ }^{1, *}$ and Jinhua Cheng ${ }^{2}$ \\ 1 School of Law and Business, Wuhan Institute of Technology, Wuhan 430205, China; \\ unicorncorncornne@gmail.com \\ 2 School of Economics and Management, China University of Geoscience, 388 Lumo Road, \\ Wuhan 430074, China; chengjinhua100@126.com \\ * Correspondence: youzhe@wit.edu.cn (Z.Y.); gongmengqi@wit.edu.cn (M.G.)
}

check for updates

Citation: Wu, T.; You, Z.; Gong, M.; Cheng, J. Star Wars? Space Weather and Electricity Market: Evidence from China. Energies 2021, 14, 5281. https://doi.org/10.3390/en14175281

Academic Editor: Yuji Yamada

Received: 29 July 2021

Accepted: 13 August 2021

Published: 26 August 2021

Publisher's Note: MDPI stays neutral with regard to jurisdictional claims in published maps and institutional affiliations.

Copyright: (C) 2021 by the authors. Licensee MDPI, Basel, Switzerland. This article is an open access article distributed under the terms and conditions of the Creative Commons Attribution (CC BY) license (https:// creativecommons.org/licenses/by/ $4.0 /)$.

\begin{abstract}
This paper aims to investigate the impact of space weather on China's electricity market. Based on data products provided by NOAA and the National Energy Administration in China, this paper uses solar wind velocity as a solar weather indicator and the disturbance storm time index as a magnetospheric weather indicator to match monthly Chinese electricity market data over 10 years. Based on a VAR model, we found that (1) space weather increases the demand for electricity in China, and solar wind speed and the geomagnetic index increase the electricity consumption of the whole of Chinese society, as space weather mainly increases the electricity consumption of the secondary and industrial sectors. (2) The geomagnetic index significantly promotes power station revenue. (3) Space weather is associated with increased energy consumption. The geomagnetic index significantly increases the coal consumption rate of fossil power plants in China, but the solar wind speed has nothing to do with the coal consumption rate of fossil power plants.
\end{abstract}

Keywords: space weather; solar wind; geomagnetic; electricity sales; power demand; coal consumption

\section{Introduction}

A clear understanding of the power market trends and influencing factors not only contributes to more scientific power system planning but also contributes to better the implementation of energy conservation and coal emission reduction policies. Many physicists have proven that space weather has a disastrous impact on electricity infrastructure. Space weather could largely change the temperature conditions, global navigation satellite systems, and power grids, which play key roles in the electricity market. However, little economic literature focusses on how space weather influences the electricity market. As dangerous space weather phenomena frequently occur and with large amounts of uncertainty, these events cost the world more than USD 2.7 trillion every year [1] and will be the biggest black swan events over the course of the next decade, as reported by Deutsche Bank. It is significant to examine the impact of space weather on the electricity market.

This paper adopts solar wind velocity (Vsw) as the index of solar activity and the disturbance storm time index (Dst) as the index of geomagnetic activity. We then match them with monthly electricity market data from over the past 10 years. This work is based on a VAR (vector autoregression) model to measure the impact of space weather on the Chinese electricity market, including electric energy consumption, sales and benefits for power station, and the coal consumption ratio of the power supply.

The research contributes to the literature in three ways: (1) it provides empirical evidence on space weather for identifying and evaluating the factors influencing power demand, which is conducive to more scientific planning for power industry development. (2) It provides evidence that space weather increases the energy consumption of electric coal and provides a new perspective for the implementation of energy conservation and emission reduction policies. (3) A quantitative study of the effects of space weather on 
economic agents in low-latitude areas is provided, while the existing literature focuses on the economic effects of space weather on high-latitude countries.

\section{Literature Review}

\subsection{Space Weather}

Space weather is a branch of space physics that is concerned with the time varying conditions within the solar system, emphasizing the space surrounding the Earth, and includes two parts: the solar activity and the geomagnetic activity. Solar storms and Geomagnetic storms occur frequently and with high uncertainty. Dangerous levels of solar and geomagnetic storms could occur every 3 years, and storms of disastrous levels could occur every 25 years.

There are many instances of these storms that have had a disastrous impact on the Earth over the course of history. The solar and magnetic storms of May 1921 contributed to the collapse of New York's power system, overheating the telegraph system and causing train stations to burn down [2]. Additionally, telegraphic communications were bad in many parts of Japan on the day of main perturbation of the magnetic storm that occurred from from 14 May 1921 21:00 to 15 May 1921 11:00. The Wellington event of August 1959 was the largest solar storm event on record, causing massive telegraph system failures and blackouts worldwide [3]. In March 1983, extremely violent solar activity triggered the most intense electromagnetic storm of the last century and greatly disrupted the ionosphere, leading directly to worldwide power system disruptions [4]. The storm affected Quebec City's power system the most severely, where transformers and capacitors tripped directly, experienced rapid voltage fluctuations, and the local population of 6 million people suffered severe economic losses. Meanwhile, numerous reports of communication channel failures and alarms occurred in United Kingdom, as the super grid transformers at Norwich Main and Indian Queens were switched out of service with damaged core bolt insulation and overheating.

\subsubsection{Solar Activity}

Solar activity modulates a flux of galactic cosmic rays that influence the Earth's atmosphere and its reflectance to the energy flux coming from the Sun. This can induce longterm trends of the Earth's climate and can sometimes lead to great weather abnormalities.

Physicists usually use the velocity of solar wind to measure how active the solar activity is. Solar wind is plasma emitted from the sun that has huge magnetic energy in its interior [5].

\subsubsection{Geomagnetic Activity}

The magnetosphere is a region of space surrounding the Earth in which the primary magnetic field is the Earth's magnetic field, which is formed by the interaction of the solar wind with the Earth's magnetic field [6]. Geomagnetic activity is caused by changes in the solar wind with the effective transfer of energy that results in significant changes in the currents and the plasma of the Earth's magnetosphere. Physicists usually use the dst index to measure how active the geomagnetic activity is. The dst index describes the temporal development of magnetic storms and the intensity of the ring current [7].

\subsection{Space Weather and Electricity Market}

There is little evidence in the economic literature that shows that space weather may have an impact on electricity markets. Based on daily power price data from 2000 to 2001 in the USA, it was found that stronger geomagnetic activity drives a significant increase in real-time power prices [8]. As unfavorable space weather conditions could inhibit power transmission, space weather is hypothesized to impede the transmission of power from low-cost to high-cost zones and thus to increase the dispersion in prices across zones. Additionally, in China, because there is a lack of liberalization in the energy trade market, it is hard to measure how space weather impacts price. However, no quantitative 
research has been done to explore the relationship between space weather and power demand or the power station revenue and non-renewable energy consumption during electricity generation. To explore more areas of how space weather impacts the electricity market, in this paper, we mainly focus on how space weather influences the electric energy consumption of society, the power station revenue, and the coal consumption rate of fossil plants.

\section{Theory}

\subsection{Temperature Channel}

Space weather can influence the temperature and in turn can influence the electricity market. For solar activity, early literature showed that solar brightness was the main cause of global warming before the industrialization of the Earth, while after the industrialization of the Earth, the influence of space brightness on the Earth's climate was reduced [9] and became insignificant. However, under the technical conditions of those scholars at that time, the possibility that ultraviolet light and magnetized plasma output from solar activity were important contributors to climate change could not be ruled out [10]. Actually, there have recently been many scholars who have noted that solar activity could drive the long-wave radiation flux to high latitude regions of the Earth, which increases the temperature of atmosphere and world's oceans [11]. Additionally, high-energy electrons released by solar activity will further destroy stratospheric ozone, further enhancing ultraviolet radiation to the Earth's surface and raising atmospheric temperatures.

Geomagnetic activity, on the other hand, drives long-wave radiation that significantly alters the Earth's atmospheric and oceanic temperatures [12]. Similar to solar activity, geomagnetic activity releases energetic electrons that break the ozone layer, thereby increasing the Earth's exposure to ultraviolet radiation and energetic particles and raising atmospheric temperatures [13]. Moreover, ionization would have a chemical interaction with the energetic electrons from solar and geomagnetic activities, providing a large amount of particles [14]. These greenhouse gases can further contribute to global warming. Although it is worth noting that the influence of geomagnetic activity on temperature is mainly concentrated in the high-latitude region [15], there are still a large amount of evidence that shows that the impact of space weather on middle- and low-latitude areas exist [16].

These temperatures could then affect the electricity market [17]. First, as the climate warms, consumers considering environmental factors will shift from energy sources such as oil and fuel to electric energy [18]. Second, as the temperature rises, consumers have cooling demands, which will increase the amount of electricity used for cooling, which, in turn, will increase the demand for electricity [19] and the revenue of electricity producers [20]. However, in the winter, consumers would have less heating demands, which might, in turn, decrease the power demand and power station revenue [21]. Multivariate regression analysis was used to discuss and confirm that U.S. electricity and natural gas consumption is affected by climate change factors such as temperature, relative humidity, and wind speed in the USA. Some scholars have discussed the relationship between higher temperatures and the increased electricity demand in Athens, Greece, the United Kingdom, and Australia $[18,22,23]$. When the temperature is low, the electricity demand increases as the temperature decreases because of the need for heating; when the temperature is high, electricity demand increases as the temperature increases because of the cooling demand.

\subsection{Global Navigation Satellite System (GNSS) Channel}

Space weather has a relationship with the global navigation satellite system (GNSS), and the GNSS plays a significant role in the electricity market. The time-stamping service is reliant on timing devices and increasingly on the Global Navigation Satellite System (GNSS), such as China's BeiDou Navigation Satellite System. Power stations, substations, and dispatching centers need the timing devices of the Global Navigation Satellite System (GNSS) to record the correct time and system switching sequence and for the protection actions for power system automation, power grid equipment operation, and grid 
mishaps [24]. As the timing devices become damaged when the GNSS is impacted by space weather, the wasted electricity in transmission and generator systems would increase.

Additionally, satellite systems could be greatly damaged by solar storms [25]. In history, plasma from solar wind and the magnetosphere have reduced the operational efficiency of geosynchronous orbit satellites. On Halloween 2003, a combination of solar and magnetic storms caused 19 satellites to fail completely and 47 satellites to show anomalies. Satellites exposed to this harsh environment are subject to episodes of deep dielectric charging, surface charging, solar panel degradation, single event upsets, and other deleterious effects. Either suddenly or gradually over time, such effects can cause catastrophic or simply lifetime-shortening consequences for satellite systems [26]. Furthermore, when the Sun and the magnetosphere add extra energy to the low-density layers of atmosphere at low Earth orbit (LEO) altitudes, the spacecraft then flies through the higher-density layer and experiences a stronger drag force [27]. Artificial satellites would then move away from their intended orbits, thereby interfering with operational efficiency.

The interaction of the solar wind with the magnetic field also has a relationship with disturbances in the ionosphere. As satellite signals from GNSS pass through the ionosphere, they are refracted and diffracted by these disturbances. The disturbed signals that are observed by a receiver on the ground may cause a loss of lock or cycle slips.

\subsection{Power Grid and Pipeline Channel}

Space weather can directly impact the power grid and pipeline. Geomagnetic storms can dramatically change the Earth's intrinsic magnesphere, generating an electromagnetic induction effect, which promotes a geomagnetically induced current (GIC) among closed-loop systems between transformers and transmission lines. This results in network equipment damage and other chain failures, and in serious cases, it can even cause widespread power mishaps and other vicious accidents.

Because of aeromagnetic measurements, power grids, pipelines, and other technical product operations are based on a geomagnetic induced effect [28], while the geomagnetic activity significantly disturbs the geomagnetic induced currents, the geomagnetic activity could result in a loss of efficiency in the power supply system [29].

As grid losses can contribute to electricity being wasted during transportation, electricity consumers need to use more electricity to achieve the same utility. This, in turn, drives demand for electricity throughout society. For power producers, because there is a lot of power loss in the power supply process, power producers need to increase production to make up for the power loss in the supply process, meaning that the power producers will sell more power and will then make more profit.

\subsection{Space Weather and Consumption Rate of Fossil Power Planet}

The coal consumption rate of a power supply refers to the amount of standard coal consumed by a power plant to supply one kilowatt-hour of electricity to the grid and is an overall indicator of the operating economy of fossil power plants.

When fossil power plants generate electricity, power stations generate apparent power with a combination of active power and reactive power. The active power is the real power that is dissipated in the circuit, whereas the reactive power moves back and forth between the load and the source. The geomagnetically induced current (GIC) effect caused by geomagnetic activity promotes the saturation of the magnetic core of the transformers and the power station, which causes the depletion of reactive consumption. As such, power stations need to generate more reactive power with more coal consumption in order to supply the same amount of electricity. This means that the coal consumption of fossil power plants would increase [30]. 


\section{Design}

4.1. Data

\subsubsection{Independent Variables}

As has shown in the literature review, this work use vsw as a proxy for solar activity because vsw measures the solar wind stream traversing the interplanetary field, which is close to the Earth. Additionally, vsw can always capture extreme solar activity. We can then use dst to measure geomagnetic activity because this measure describes the temporal development of magnetic storms and the intensity of the ring current for low and mid-latitudes. Additionally, the dst value is more precise than other indexes such as the geomagnetic $\mathrm{Kp}$ index, which only creates values with integers from 0 to 9 . However, the dst index is usually negative, and the smaller the dst index is, the more severe the geomagnetic activity is when the dst index is negative. Additionally, if the dst index is positive, the geomagnetic activity is very calm and has little impact on the Earth. For the convenience of this research, we used the method proposed by Forbes [8]. We first change the positive part of the dst index to zero, which implies that the geomagnetic activity is calm. Additionally, we change the negative data to the positive index; the larger the new dst index is, the stronger the geomagnetic activity is.

\subsubsection{Dependent Variables}

Dependent variables include society's electric energy consumption, the benefit to power stations, and the coal consumption rate of the power supply. The monthly power station data are available from May 2003 to February 2013, the monthly data for the coal consumption rate of fossil power plants are available from February 2005 to March 2019, and the monthly data for electricity consumption are available from July 2009 to March 2019. The missing data during the selected period were dropped. The space weather data used in our analysis are provided by the Advanced Composition Explorer (ACE) Satellite Data from NASA and the World Data Center for Geomagnetism, Kyoto. The electricity market data are provided by China Stock Market \& Accounting Research Database (CSMAR) and the Chinese Economic Information Database (CEI). These databases collect electricity market data that are originally from the National Energy Administration in China.

\subsection{Model}

This paper adapts a Var model [31] to estimate the relationship between space weather and electricity in China.

$$
Y_{t}=c+\sum_{j=1}^{p} \beta_{J} Y_{t-j}+\sum_{i=1}^{r} \gamma_{i} X_{t-i}+\mu_{t}
$$

$Y_{t}$ denotes the $t$ period independent variable in the model, $Y_{t-j}$ and $X_{t-j}$ denote the independent variable of $p$ lag length and the dependent variable of $r$ lag length, respectively. $c$, $\beta_{J}, \gamma_{i}$ indicate the parameters to be evaluated, and $\mu_{t}$ denotes the random perturbation. Additionally, the optimal lag length of the explained and explanatory variables are determined by the minimum values in the AIC (the Akaike information criterion) or the FPE (Akaike's Final Prediction Error) criterion. AIC is an estimator of prediction error and thereby for the relative quality of statistical models for a given set of data, while the FPE criterion provides a measure of model quality by simulating the situation where the model is tested on a different data set. AIC and FPE both have the minimum values if the lag length concerning the explained and explanatory variables is optimal. After logging the coal consumption, electricity consumption, and power station benefit, we performed an ADF test on all of the variables, and the variables passed the stationarity test. 


\section{Main Result}

\subsection{Space Weather and Power Demand}

Table 1 shows the AIC information concerning the electricity consumption for the whole of society. The optimal lag length is three, as an AIC lag length of three is the minimum. The stability test was then performed using the AR root test method. The model is stable if the modulus of all of the AR roots in the model and the reciprocal of their values are less than 1 . Additionally, the data pass the balance test, as all of the dots are in the circle, which is shown in Figure 1.

Table 1. Optimal lag length concerning the electricity consumption of the whole of society.

\begin{tabular}{ccccccc}
\hline Lag & LL & LR & df & P & FPE & AIC \\
\hline 0 & -725.922 & - & - & - & 790.165 & 15.1859 \\
1 & -639.735 & 172.37 & 9 & 0.000 & 158.272 & 13.5778 \\
2 & -628.913 & 21.643 & 9 & 0.010 & 152.476 & 13.5399 \\
3 & -616.567 & $24.692 *$ & 9 & 0.003 & $142.422 *$ & $13.4701^{*}$ \\
4 & -613.411 & 6.3116 & 9 & 0.708 & 161.305 & 13.5919 \\
\hline
\end{tabular}

* represents the indicator satisfy the requirement of optimal lag length.

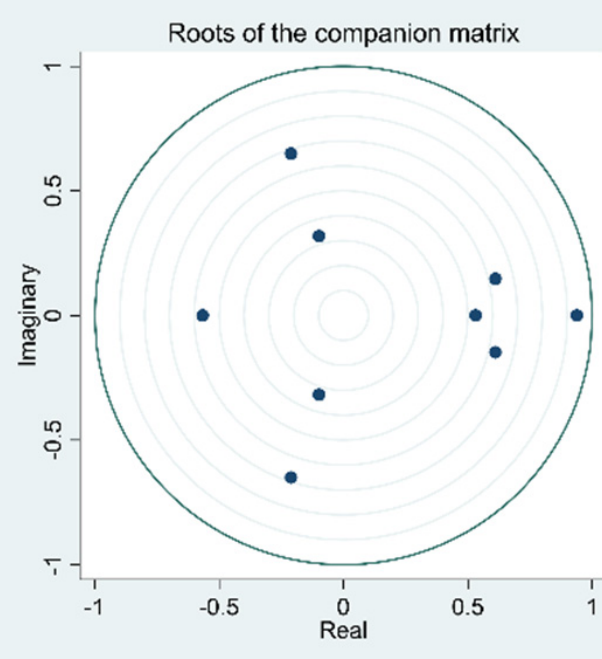

Figure 1. Balance test of data concerning the electricity consumption of the whole of society.

Table 2 shows that the vsw index can significantly promote the electricity consumption of the whole of society and can pass the $90 \%$ robustness test. Additionally, the dst index can increase the electricity consumption of the whole of society and can pass the $95 \%$ robustness test. The Var model as the impulse response analysis studies the effect of the changes of the error term on the system, which is the Granger causality. Though the empirical results cannot present the true causality, the Granger causality can still test whether one time series $\mathrm{S}$ is the changing factor of another time series $\mathrm{T}$. It tests whether the prediction result of the time series variable $\mathrm{T}$ when the past information of time series $\mathrm{S}$ and $\mathrm{T}$ are both known and is more effective than the prediction of time series $\mathrm{T}$ by using the past information of $\mathrm{T}$ alone rather than using the direct impact between the indicators. Figure 2 is the impulse response function graph that shows the Granger causality between the electricity consumption of the whole of society and space weather. Additionally, we can learn from Figure 2 that during the optimal lag period, society's electricity consumption increased, responding to the dst and vsw index, which means that the solar activity and geomagnetic activity can explain the promotion of the electricity consumption of society. During the first period, the electricity consumption of the society decreased, responding to dst; however, during the second and third period, the consumption increased and did 
not responded to the dst later. Additionally, society's electricity construction positively responded to the vsw from the first period to the seventh period.

Table 2. Dpace weather and electricity consumption of the whole of society.

\begin{tabular}{cccccc}
\hline Equation & Exluded & F & Df & df_r & Prob $>$ F \\
\hline Social & vsw & $2.6217^{*}$ & 3 & 87 & 0.0557 \\
Social & dst & $3.5479^{* *}$ & 3 & 87 & 0.0178 \\
Social & ALL & $1.9913^{*}$ & 3 & 87 & 0.0755 \\
\hline
\end{tabular}

${ }^{*}$ represents statistical level at $10 \%,{ }^{* *}$ at $5 \%$, and ${ }^{* * *}$ at $1 \%$, respectively.

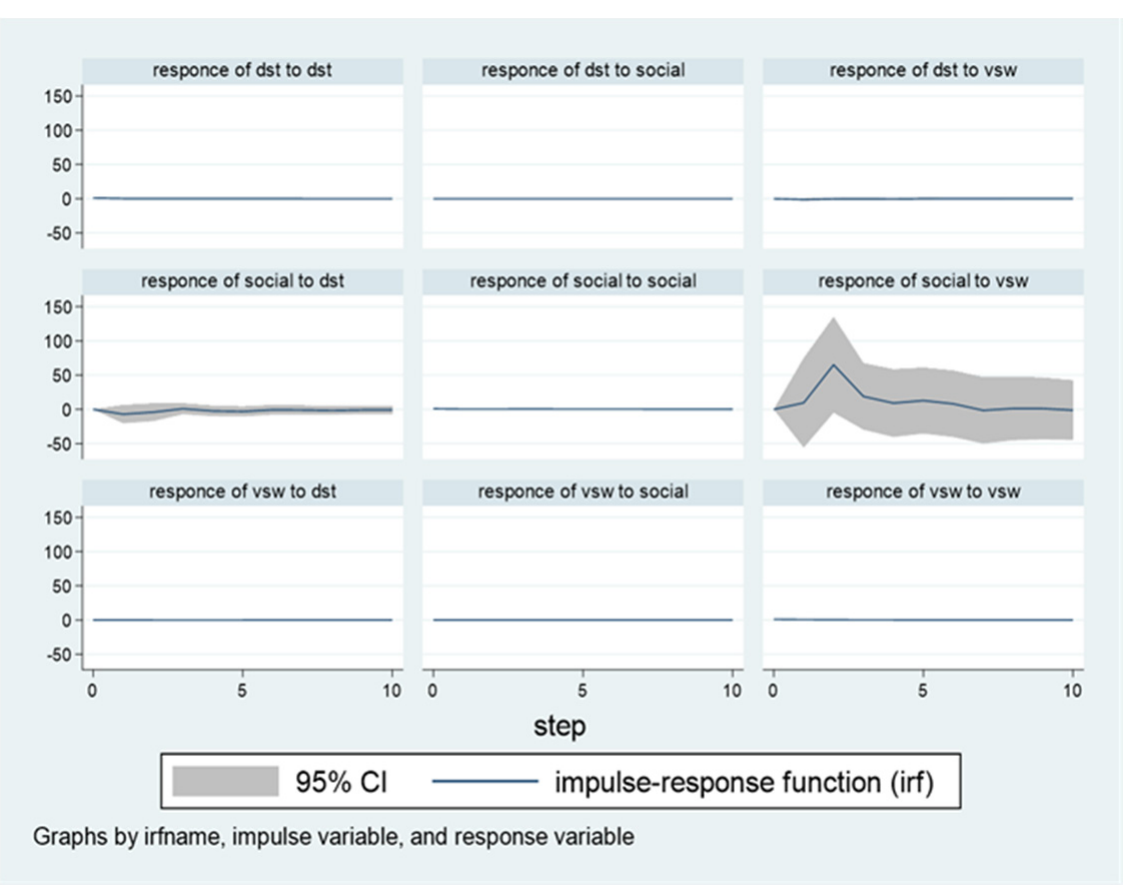

Figure 2. Response of electricity consumption of the whole of society to space weather.

Table 3 shows the AIC information concerning the electricity consumption of the secondary sector. The optimal lag length is three, as an AIC lag length of three is the minimum, and the data pass the balance test, as all of the dots are in the circle, which is shown in Figure 3.

Table 3. Optimal lag length concerning the electricity consumption of the whole of society.

\begin{tabular}{ccccccc}
\hline Lag & LL & LR & df & P & FPE & AIC \\
\hline 0 & -722.57 & - & - & - & 736.867 & 15.116 \\
1 & -670.061 & 105.02 & 9 & 0.000 & 297.712 & 14.2096 \\
2 & -658.468 & 23.187 & 9 & 0.006 & 282.233 & 14.1556 \\
3 & -640.306 & $36.325^{*}$ & 9 & 0.000 & $233.538^{*}$ & $13.9647^{*}$ \\
4 & -638.157 & 4.297 & 9 & 0.891 & 270.11 & 14.1074 \\
\hline
\end{tabular}

${ }^{*}$ represents statistical level at $10 \%,{ }^{* *}$ at $5 \%$, and ${ }^{* * *}$ at $1 \%$, respectively. 


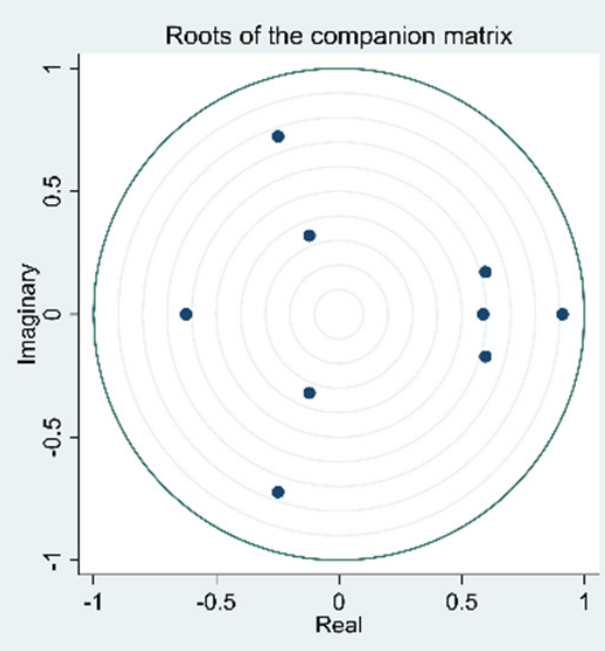

Figure 3. Balance test of data concerning the electricity consumption of the secondary sector.

Table 4 shows that the vsw index can significantly promote the electricity consumption of the secondary sector and can pass the $99 \%$ robustness test. Additionally, the dst index can increase the electricity consumption of the secondary sector and can also pass the $99 \%$ robustness test. Additionally, we can learn from Figure 4 that during the optimal lag period, society's electricity consumption increased, responding to dst and vsw index, which means that solar activity and geomagnetic activity can help to explain the promotion of electricity consumption in the secondary sector.

Table 4. Space weather and electricity consumption of the secondary sector.

\begin{tabular}{cccccc}
\hline Equation & Exluded & F & Df & df_r & Prob $>$ F \\
\hline Secondary & vsw & $4.7163^{* * *}$ & 3 & 87 & 0.0043 \\
Secondary & dst & $4.4677^{* * *}$ & 3 & 87 & 0.0058 \\
Secondary & ALL & $2.893^{* *}$ & 3 & 87 & 0.0128 \\
\hline
\end{tabular}

${ }^{*}$ represents statistical level at $10 \%,{ }^{* *}$ at $5 \%$, and ${ }^{* * *}$ at $1 \%$, respectively.

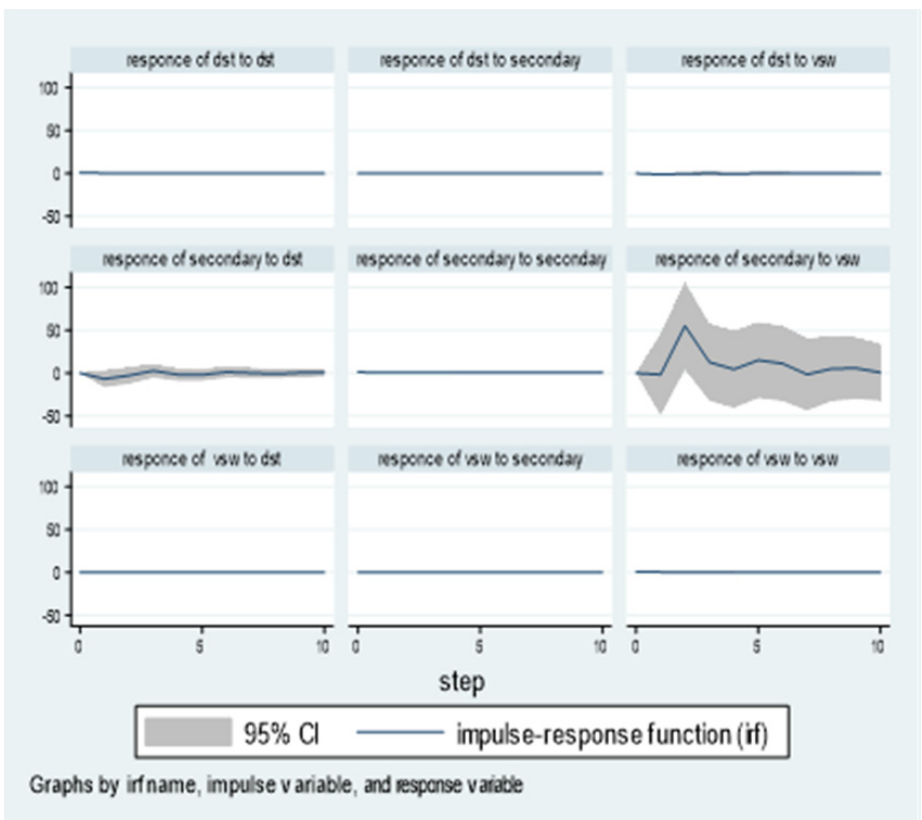

Figure 4. Response of electricity consumption of the secondary sector to space weather. 
Table 5 shows the AIC information concerning the electricity consumption of the secondary sector. The optimal lag length is three, as an AIC lag length of three is the minimum, and the data pass the balance test, as all of the dots are in the circle, which is shown in Figure 5.

Table 5. Optimal lag length concerning the electricity consumption of the industry sector.

\begin{tabular}{ccccccc}
\hline Lag & LL & LR & df & P & FPE & AIC \\
\hline 0 & -722.764 & - & - & - & 739.854 & 15.1201 \\
1 & -671.128 & 103.27 & 9 & 0.000 & 304.4 & 14.2318 \\
2 & -659.556 & 23.143 & 9 & 0.006 & 288.704 & 14.1783 \\
3 & -641.325 & $36.462 *$ & 9 & 0.000 & $238.552 *$ & $13.9859^{*}$ \\
4 & -639.152 & 4.346 & 9 & 0.887 & 275.769 & 14.1282 \\
\hline
\end{tabular}

${ }^{*}$ represents statistical level at $10 \%,{ }^{* *}$ at $5 \%$, and ${ }^{* * *}$ at $1 \%$, respectively.

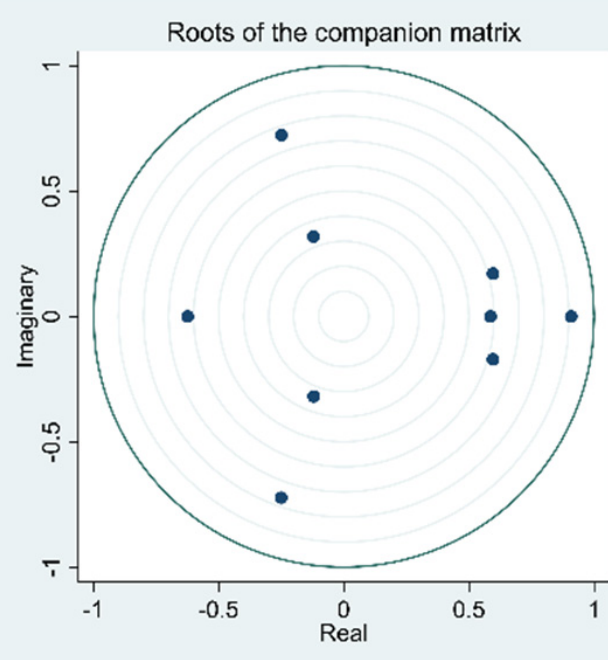

Figure 5. Balance test of data concerning the electricity consumption of the industry sector.

Table 6 shows that the vsw index can significantly promote electricity consumption in the industry sector and can pass the $99 \%$ robustness test. Additionally, the dst index can increase the electricity consumption of the industry sector and can also pass the $99 \%$ robustness test. Additionally, we can learn from Figure 6 that during the optimal lag period, the electricity consumption of the industry increased, responding to the dst and vsw index, which means that the solar activity and geomagnetic activity can promote the electricity consumption of the industry sector.

Table 6. Space weather and electricity consumption of the industry sector.

\begin{tabular}{cccccc}
\hline Equation & Exluded & F & Df & df_r & Prob > F \\
\hline Industry & vsw & $4.7454^{* * *}$ & 3 & 87 & 0.0041 \\
Industry & dst & $4.4919^{* * *}$ & 3 & 87 & 0.0056 \\
Industry & ALL & $2.908^{* *}$ & 6 & 87 & 0.0124 \\
\hline
\end{tabular}

${ }^{*}$ represents statistical level at $10 \%,{ }^{* *}$ at $5 \%$, and ${ }^{* * *}$ at $1 \%$, respectively. 


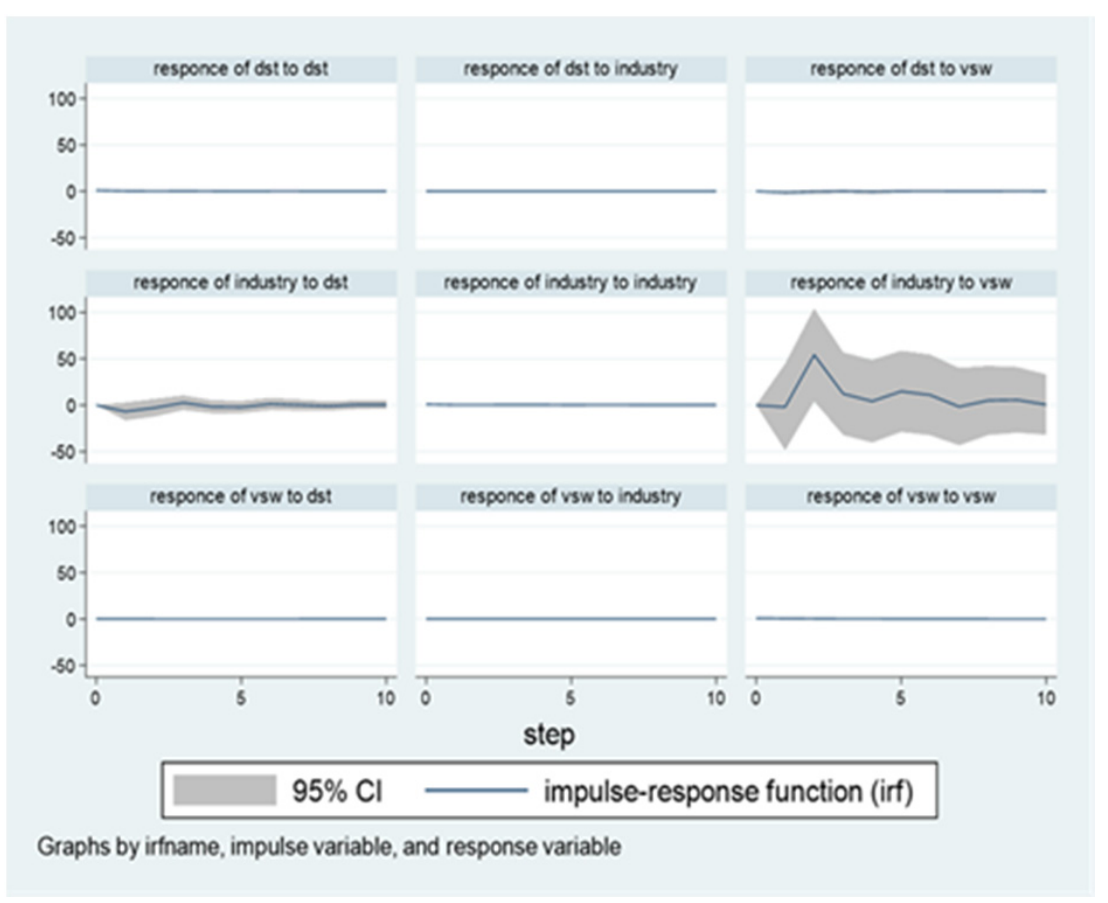

Figure 6. Response of electricity consumption of the industry sector to space weather.

Table 7 shows the AIC information concerning power station revenue. The optimal lag length is two, as an AIC lag length of three is the minimum, and the data pass the balance test, as all of the dots are in the circle, which is shown in Figure 7.

Table 7. Optimal lag length concerning the power station revenue.

\begin{tabular}{ccccccc}
\hline Lag & LL & LR & df & P & FPE & AIC \\
\hline 0 & -841.387 & - & - & - & 108,102 & 20.1045 \\
1 & -788.909 & 104.96 & 9 & 0.000 & $38,401.1$ & 19.0693 \\
2 & -779.189 & $19.44^{*}$ & 9 & 0.022 & $37,784.2^{*}$ & $19.0521^{*}$ \\
3 & -775.806 & 6.7651 & 9 & 0.662 & $43,288.3$ & 19.1859 \\
4 & -768.203 & 15.206 & 9 & 0.085 & 44,937 & 19.2191 \\
\hline
\end{tabular}

${ }^{*}$ represents statistical level at $10 \%,{ }^{* *}$ at $5 \%$, and ${ }^{* * *}$ at $1 \%$, respectively.

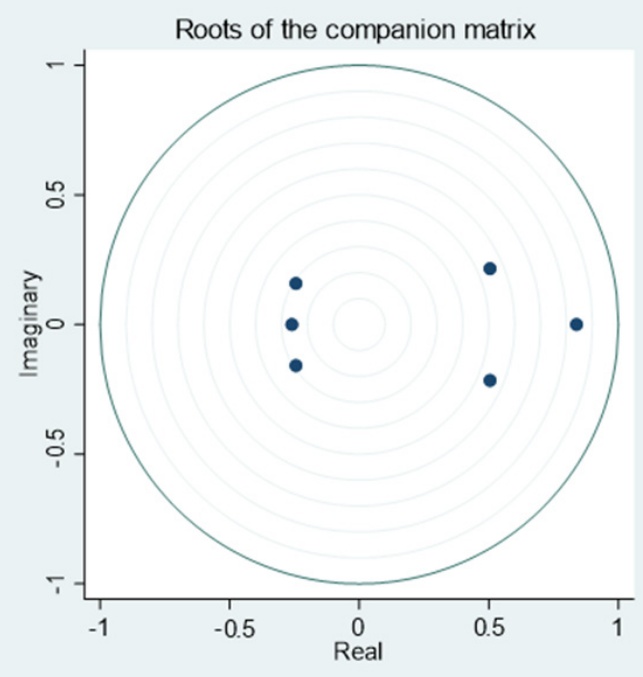

Figure 7. Balance test of data concerning power station revenue. 


\subsection{Space Weather and Revenue of Power Station}

Table 8 shows that the vsw does not have a significant impact on power station revenue. However, the dst index can help to explain the increase in the power station revenue and can pass the $90 \%$ robustness test. Additionally, we can learn from Figure 8 that during the optimal lag period, power station revenue increased, responding to the dst, which means that geomagnetic activity can help to explain the promotion of power station revenue. The power station revenue responded positively to the dst index from the first period to the third period.

Table 8. Space weather and power station revenue.

\begin{tabular}{lccccc}
\hline Equation & Exluded & F & Df & df_r & Prob > F \\
\hline Revenue & vsw & 0.49033 & 2 & 79 & 0.6143 \\
Revenue & dst & $2.8542^{*}$ & 2 & 79 & 0.0636 \\
Revenue & ALL & 2.0503 & 4 & 79 & 0.0953 \\
\hline
\end{tabular}

${ }^{*}$ represents statistical level at $10 \%,{ }^{* *}$ at $5 \%$, and ${ }^{* * *}$ at $1 \%$, respectively.

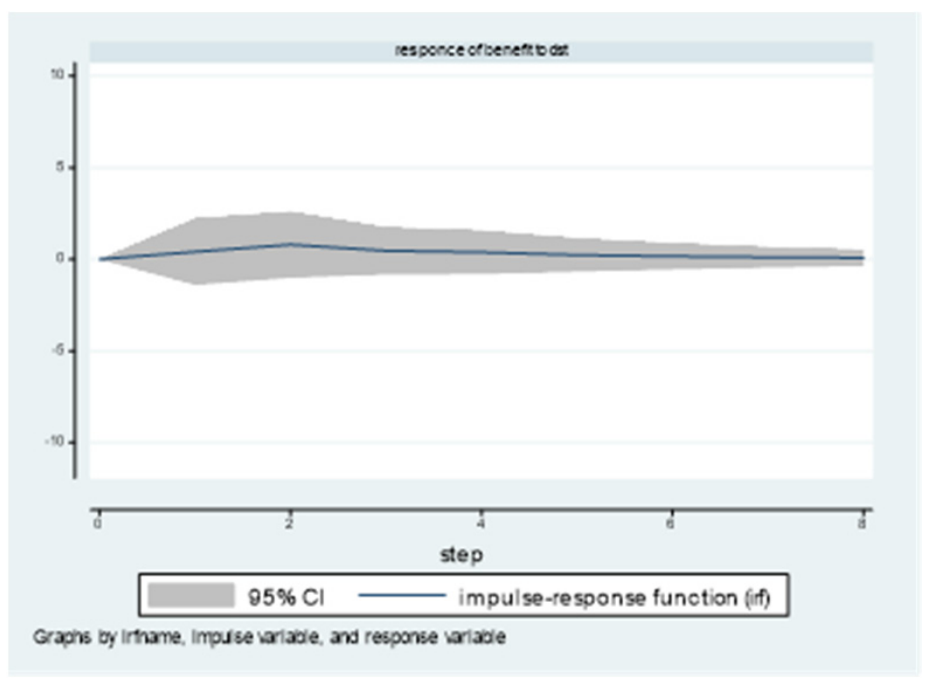

Figure 8. Response of power station revenue to space weather.

\subsection{Space Weather and Coal Consumption Rate of Fossil Planet}

Table 9 shows the AIC information concerning the coal consumption rate of fossil power plants. The optimal lag length is two, as an AIC lag length of three is the minimum, and the data pass the balance test, as all of the dots are in the circle, which is shown in Figure 9.

Table 9. Optimal lag length concerning the coal consumption rate of fossil power plants.

\begin{tabular}{ccccccc}
\hline Lag & LL & LR & df & P & FPE & AIC \\
\hline 0 & -1725.11 & - & - & - & $1.5 \times 10^{7}$ & 25.045 \\
1 & -1418.55 & 613.11 & 9 & 0.000 & 202,615 & 20.7326 \\
2 & -1408.24 & 20.627 & 9 & 0.014 & $198,836^{*}$ & $20.7136^{*}$ \\
3 & -1403.62 & 9.2371 & 9 & 0.416 & 211,978 & 20.7771 \\
4 & -1393.85 & $19.549^{*}$ & 9 & 0.021 & 209,804 & 20.7659 \\
\hline
\end{tabular}

* represents statistical level at $10 \%,{ }^{* *}$ at $5 \%$, and ${ }^{* * *}$ at $1 \%$, respectively. 


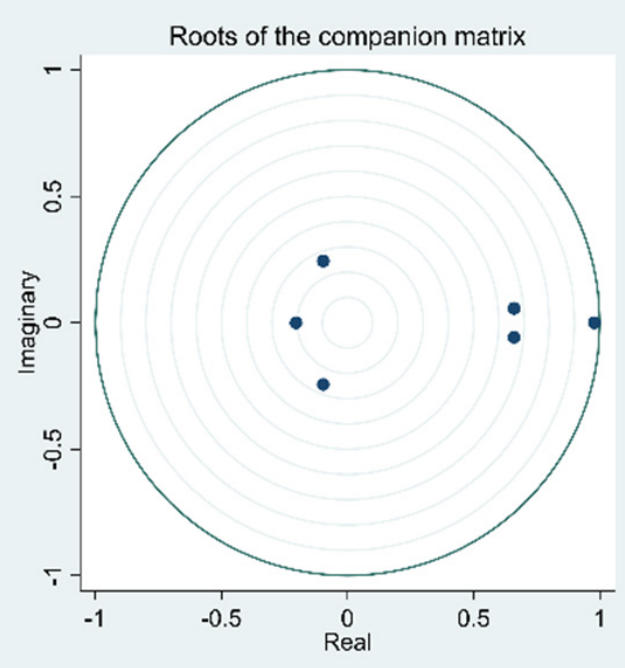

Figure 9. Balance test of data concerning the coal consumption rate of fossil power plants.

Table 10 shows that the vsw does not have a significant impact on the coal consumption of fossil power plants. However, the dst index can increase the coal consumption of fossil power plants and can pass the $90 \%$ robustness test. Additionally, we can learn from Figure 10 that during the optimal lag period, the coal consumption rate of fossil power plants increased, responding to dst, which means that geomagnetic activity can help explain the promotion of the coal consumption rate of fossil power plants.

Table 10. Space weather and coal consumption rate of fossil power plants.

\begin{tabular}{ccccc}
\hline Equation & Exluded & chi2 & df & Prob > chi2 \\
\hline Coal & Vsw & 3.3318 & 2 & 0.189 \\
Coal & Dst & $5.7224^{*}$ & 2 & 0.057 \\
Coal & ALL & 6.7428 & 4 & 0.150 \\
\hline
\end{tabular}

${ }^{*}$ represents statistical level at $10 \%,{ }^{* *}$ at $5 \%$, and ${ }^{* * *}$ at $1 \%$, respectively.

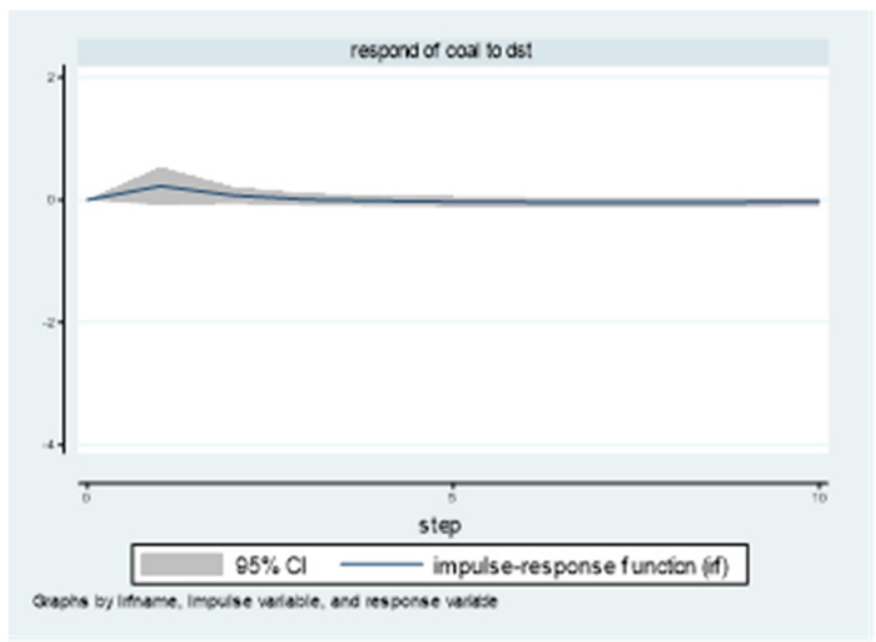

Figure 10. Response of coal consumption rate of fossil power plants.

The coal consumption rate of fossil power plants responded positively to the dst index from the first period to the second period. 


\section{Conclusions}

This work examined the impact of space weather on the electricity market in low- and middle-latitude areas. Using the vsw as a proxy for solar activity and the dst as a proxy for geomagnetic activity, the results show that solar activity and geomagnetic activity can promote societal electric energy consumption and in the secondary sector and industry sector in particular. Additionally, geomagnetic activity can promote the power station revenue and the coal consumption rate of fossil plants.

Based on the results, it is suggested that the Chinse government should consider more astrophysical factors for the implementation of energy conservation and emission reduction policies. Thus, astrophysical topics should be given more attention when developing physics textbooks to be used in general education. What is more, space weather forecasting should be improved in order to protect the electricity market in advance. The Chinese National Space Administration should launch more satellites to observe variable kinds of space weather data from different positions in space, which is the base of promoting the forecasting ability using historic data. Additionally, investment in technology for protecting power grids and power stations from being damaged by geomagnetic forces, inducing a currency effect caused by geomagnetic activity should be given high consideration.

Author Contributions: T.W. and Z.Y. designed the study, analyzed the data, and wrote the manuscript. Z.Y. and M.G. collected the data and coordinated the data analysis. J.C. and Z.Y. revised the manuscript. All authors have read and agreed to the published version of the manuscript.

Funding: This research is supported by grants from the National Natural Science Foundation of China (Grant 71991482).

Data Availability Statement: Not applicable.

Conflicts of Interest: The authors declare no conflict of interest.

\section{References}

1. Eastwood, J.P.; Biffis, E.; Hapgood, M.A.; Green, L.; Bisi, M.M.; Bentley, R.D.; Wicks, R.; McKinnell, L.-A.; Gibbs, M.; Burnett, C. The Economic Impact of Space Weather: Where Do We Stand? Risk Anal. 2017, 37, 206-218. [CrossRef]

2. Love, J.J.; Hayakawa, H.; Cliver, E.W. Intensity and Impact of the New York Railroad Superstorm of May 1921. Space Weather 2019, 17, 1281-1292. [CrossRef]

3. Boteler, D. The super storms of August/September 1859 and their effects on the telegraph system. Adv. Space Res. 2006, 38, 159-172. [CrossRef]

4. Boteler, D.H. A 21st Century View of the March 1989 Magnetic Storm. Space Weather 2019, 17, 1427-1441. [CrossRef]

5. Tritakis, V.; Korbakis, G.; Nastos, P.; Paliatsos, A.; Pisanko, Y. Ozone destruction by solar electrons in relation to solar variability and the terrestrial latitude. Adv. Space Res. 2008, 43, 659-664. [CrossRef]

6. Rowland, D.E.; Wygant, J.R. Dependence of the large-scale, inner magnetospheric electric field on geomagnet-ic activity. J. Geophys. Res. Space Phys. 1998, 103, 14959-14964. [CrossRef]

7. Mursula, K.; Tanskanen, E.; Love, J. Spring-fall asymmetry of substorm strength, geomagnetic activity and solar wind: Implications for semiannual variation and solar hemispheric asymmetry. Geophys. Res. Lett. 2011, 38. [CrossRef]

8. Forbes, K.F.; St Cyr, O.C. Space weather and the electricity market: An initial assessment. Space Weather 2004, 2. [CrossRef]

9. Lockwood, M.; Fröhlich, C. Recent oppositely directed trends in solar climate forcings and the global mean surface air temperature. Proc. R. Soc. A Math. Phys. Eng. Sci. 2007, 463, 2447-2460. [CrossRef]

10. Foukal, P.; Fröhlich, C.; Spruit, H.; Wigley, T.M.L. Variations in solar luminosity and their effect on the Earth's climate. Nature 2006, 443, 161-166. [CrossRef]

11. Zherebtsov, G.; Kovalenko, V.; Molodykh, S.; Kirichenko, K. Solar variability manifestations in weather and climate characteristics. J. Atmos. Solar Terr. Phys. 2018, 182, 217-222. [CrossRef]

12. Ahern, K. Eyes on the Skies. Science 2000, 290, 473.

13. Seppälä, A.; Lu, H.; Clilverd, M.A.; Rodger, C. Geomagnetic activity signatures in wintertime stratosphere wind, temperature, and wave response. J. Geophys. Res. Atmos. 2013, 118, 2169-2183. [CrossRef]

14. Seppälä, A.; Verronen, P.T.; Clilverd, M.A.; Randall, C.E.; Tamminen, J.; Sofieva, V.; Backman, L.; KYRöLä, E. Arctic and Antarctic polar winter NOx and energetic particle precipitation in 2002-2006. Geophys. Res. Lett. 2007, 34. [CrossRef]

15. Baumgaertner, A.J.G.; Seppälä, A.; Jöckel, P.; Clilverd, M.A. Geomagnetic activity related $\mathrm{NO}_{\mathrm{x}}$ enhancements and polar surface air temperature variability in a chemistry climate model: Modulation of the NAM index. Atmos. Chem. Phys. 2011, 11, 4521-4531. [CrossRef] 
16. Lam, M.M.; Chisham, G.; Freeman, M.P. The interplanetary magnetic field influences mid-latitude surface at-mospheric pressure. Environ. Res. Lett. 2013, 8, 045001. [CrossRef]

17. Zhang, C.; Liao, H.; Mi, Z. Climate impacts: Temperature and electricity consumption. Nat. Hazards 2019, 99, 1259-1275. [CrossRef]

18. Mirasgedis, S.; Sarafidis, Y.; Georgopoulou, E.; Kotroni, V.; Lagouvardos, K.; Lalas, D. Modeling framework for estimating impacts of climate change on electricity demand at regional level: Case of Greece. Energy Convers. Manag. 2007, 48, 1737-1750. [CrossRef]

19. Bessec, M.; Fouquau, J. The non-linear link between electricity consumption and temperature in Europe: A threshold panel approach. Energy Econ. 2008, 30, 2705-2721. [CrossRef]

20. Moral-Carcedo, J.; Vicéns-OTERO, J. Modelling the non-linear response of Spanish electricity demand to tem-perature variations. Energy Econ. 2005, 27, 477-494. [CrossRef]

21. Sailor, D.J.; MUñOZ, J.R. Sensitivity of electricity and natural gas consumption to climate in the U.S.A.-Methodology and results for eight states. Energy 1997, 22, 987-998. [CrossRef]

22. Psiloglou, B.; Giannakopoulos, C.; Majithia, S.; Petrakis, M. Factors affecting electricity demand in Athens, Greece and London, UK: A comparative assessment. Energy 2009, 34, 1855-1863. [CrossRef]

23. Ahmed, T.; Muttaqi, K.; Agalgaonkar, A. Climate change impacts on electricity demand in the State of New South Wales, Australia. Appl. Energy 2012, 98, 376-383. [CrossRef]

24. Mannix, C.R.; Belcher, D.P.; Cannon, P.; Angling, M.J. Using GNSS signals as a proxy for SAR signals: Correcting ionospheric defocusing. Radio Sci. 2016, 51, 60-70. [CrossRef]

25. Hernandez-Pajares, M.; Juan, J.M.; Sanz, J.; Bilitza, D. Combining GPS measurements and IRI model val-ues for space weather specification. Adv. Space Res. 2002, 29, 949-958. [CrossRef]

26. Thomsen, M.F.; Denton, M.H.; Lavraud, B.; Bodeau, M. Statistics of plasma fluxes at geosynchronous orbit over more than a full solar cycle. Space Weather 2007, 5. [CrossRef]

27. Andalsvik, Y.L.; Jacobsen, K.S. Observed high-latitude GNSS disturbances during a less-than-minor geomag-netic storm. Radio Sci. 2014, 49, 1277-1288. [CrossRef]

28. Molinski, T.S. Why utilities respect geomagnetically induced currents. J. Atmos. Solar Terr. Phys. 2002, 64, 1765-1778. [CrossRef]

29. Ahluwalia, H.S. North-south excess of hemispheric sunspot numbers and cosmic ray asymmetric solar modula-tion. Adv. Space Res. 2015, 56, 2645-2648. [CrossRef]

30. Xuzhu, D.; Yilu, L.; Kappenman, J.G. Comparative analysis of exciting current harmonics and reactive power con-sumption from GIC saturated transformers. In Proceedings of the 2001 IEEE Power Engineering Society Winter Meeting, Conference Proceedings (Cat. No.01CH37194), Columbus, OH, USA, 28 January-1 February 2001; Volume 1, pp. 318-322.

31. Hansen, H.; Johansen, S. Some tests for parameter constancy in cointegrated VAR-models. Econ. J. 1999, 2, 306-333. [CrossRef] 